\title{
Endothelin receptor antagonists: effects on extracellular matrix synthesis in primary cultures of skin fibroblasts from systemic sclerosis patients
}

\author{
S. Soldano ${ }^{1}$, P. Montagna ${ }^{1}$, R. Brizzolara ${ }^{1}$, C. Ferrone ${ }^{1}$, \\ A. Parodi ${ }^{2}$, A. Sulli ${ }^{1}$, B. Seriolo ${ }^{1}$, B. Villaggio' ${ }^{3}$, M. Cutolo ${ }^{1}$ \\ ${ }^{1}$ Research Laboratory and Academic Unit of Clinical Rheumatology, \\ Department of Internal Medicine, University of Genova, Italy; \\ ${ }^{2}$ Department of Health Science, Unit of Dermatology, University of Genova, Italy; \\ ${ }^{3}$ Research Laboratory of Nephrology, Department of Internal Medicine, University of Genova, Italy
}

Work awarded at XLVIII Congress of Italian Society of Rheumatology (SIR) Rimini 2011

\section{SUMMARY}

Endothelin-1 (ET-1) seems to enhance the pro-fibrotic protein synthesis by skin fibroblasts and its effects are mediated by endothelin- $\mathrm{A}$ and $\mathrm{B}\left(\mathrm{ET}_{\mathrm{A}}\right.$ and $\left.\mathrm{ET}_{\mathrm{B}}\right)$ receptors. This study aimed to investigate the effects of $\mathrm{ET}_{\mathrm{A}}$ and

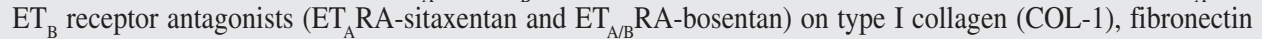
(FN) and fibrillin-1 (FBL-1) synthesis in primary cultures of skin fibroblasts from systemic sclerosis (SSc) patients. Primary cultures of fibroblasts were obtained from skin biopsies of 6 female SSc patients and were treated with ET-1 $(100 \mathrm{nM})$ for 24 and 48 hrs with or without pre-treatment $(1 \mathrm{hr})$ with $\mathrm{ET}_{\mathrm{A}} \mathrm{RA}(2 \mu \mathrm{M})$ or ET $\mathrm{A}_{\mathrm{A}}$ ${ }_{\mathrm{B}} \mathrm{RA}(10 \mu \mathrm{M})$. Primary culture of human SSc skin fibroblasts not treated with ET-1 or ET receptor antagonists (ET $\mathrm{A}_{\mathrm{A}} \mathrm{RA}$ and $\mathrm{ET}_{\mathrm{A} / \mathrm{B}} \mathrm{RA}$ ) were used as controls. COL-1, FN and FBL-1 synthesis was evaluated by immunocytochemistry and Western blot analysis. Immunocytochemistry and Western blot analysis showed that ET-1 significantly increased COL-1 and FN synthesis at 24 and 48 hrs and FBL-1 synthesis at 48 hrs vs untreated

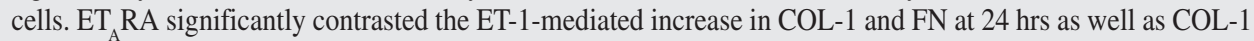

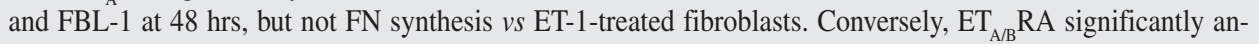
tagonized the ET-1-mediated overproduction of COL-1 and FN both at 24 and 48 hrs and the FBL-1 synthesis at $48 \mathrm{hrs} v s$ ET-1-treated cells.

The single ET $\mathrm{A}_{\mathrm{A}} \mathrm{RA}$ treatment seems to contrast significantly the increase in COL-1 synthesis, whereas the dual $\mathrm{ET}_{\mathrm{A} / \mathrm{B}}$ RA treatment seems active in significantly antagonizing both COL-1 and FN overproduction induced by ET-1. In conclusion, ET-1 antagonism might have positive effects in contrasting the profibrotic activity of systemic sclerosis skin fibroblasts.

Key words: Skin fibrosis, endothelin receptor antagonist, endothelin-1, extracellular matrix proteins, fibroblasts, systemic sclerosis.
Corresponding author: Maurizio Cutolo Direttore del Laboratorio di Ricerca e U.O.C Clinica Reumatologica Dipartimento di Medicina Interna e Specialità Mediche Università di Genova Viale Benedetto, XV/6 - 16132 Genova E-mail: mcutolo@unige.it

\section{INTRODUCTION}

n systemic scleorsis ( $\mathrm{SSc}$ ), the fibrosis of skin and internal organs is an important pathological feature and it is primarily determined by the transition of quiescent to activated fibroblasts, called myofibroblasts, that become effector cells by enhancing the synthesis and deposition of collagens and other extracellular matrix (ECM) macromolecules (1-4).

Fibrosis is regulated by a complex inter- action between cytokines and growth factors, such as transforming growth factor- $\beta$ (TGF- $\beta$ ) and endothelin-1 (ET-1) which act on different cell types involved in the fibrotic process (pericytes, mesenchymal stem cells, and fibroblasts, in particular) $(5,6)$. In a recent study, TGF- $\beta$ was shown to induce ET-1 expression in human dermal fibroblasts and promoted their differentiation to profibrotic and contractile myofibroblasts, confirming the crucial role of the TGF- $\beta /$ ET- 1 axis in the development 
of fibrosis, primarily in the skin (5). ET-1 is one of the major over-expressed soluble mediators in both early and late stage of SSc fibrosis.

This molecule, besides being a potent vasoconstrictor and a direct downstream target of TGF- $\beta 1$, acts like a pro-fibrotic cytokine stimulating fibroblast chemotaxis and proliferation, as well as inducing procollagen and fibronectin (FN) synthesis (2-7). Since ET-1 mediates its biological effects via endothelin (ET) A and B receptors on fibroblasts, there is growing evidence to suggest that antagonizing ET receptors might represent a possible strategy to block the effects of this molecule, at least in SSc skin fibrosis $(8,9)$.

The aim of the present in vitro study was to evaluate the contrasting effects of single $\mathrm{ET}_{\mathrm{A}}$ and dual $\mathrm{ET}_{\mathrm{A} / \mathrm{B}}$ receptor antagonist $\left(\mathrm{ET}_{\mathrm{A}} \mathrm{RA}\right.$ and $\mathrm{ET}_{\mathrm{A} / \mathrm{B}} \mathrm{RA}$ ) on type I collagen (COL-1), FN and fibrillin-1 (FBL-1) in primary cultures of SSc skin fibroblasts.

\section{MATERIALS AND METHODS}

\section{Cell cultures and treatments}

Skin biopsies were obtained during diagnostic procedures (Dermatology Clinic, University of Genoa, Italy) from 6 female SSc patients (mean age $64 \pm 8$ years) after informed consent and Ethical Committee approval were obtained. In order to reduce variability, study participants showed the same level of skin/disease involvement (limited SSc), and average disease duration (4.6 \pm 4 years). Ongoing treatments limited to vasodilator drugs (loftyl, iloprost) were stopped at least one month before the diagnostic procedure and subsequently restarted. Skin biopsies were cut, incubated with collagenase $0.1 \mu \mathrm{g} / \mathrm{mL}$ (Sigma-Aldrich, Milan, Italy) and finally plated in cell culture dishes in the presence of culture medium made up of RPMI 1640 at $10 \%$ of fetal bovine serum (FBS, Lonza, South America), and $1 \%$ penicillin-streptomycin and $1 \%$ of L-glutamine (Lonza) at $37^{\circ} \mathrm{C}$ $5 \%$ of $\mathrm{CO}_{2}$ to obtain skin fibroblasts. The cells were grown in culture medium until the $4^{\text {th }}$ passage. To detect the optimal con- centration able to antagonize the mitogenic effects of ET-1, a concentration range (0.1 $\mu \mathrm{M}-100 \mu \mathrm{M}$ ) for $\mathrm{ET}_{\mathrm{A}} \mathrm{RA}$ (sitaxentan) and $\mathrm{ET}_{\mathrm{A} / \mathrm{B}} \mathrm{RA}$ (bosentan) was tested before starting with the experiments. The optimal concentration found to reduce the ET- 1 effects was $2 \mu \mathrm{M}$ for ET RA and $10 \mu \mathrm{M}$ for $\mathrm{ET}_{\mathrm{A} / \mathrm{B}} \mathrm{RA}$ (data not shown), in agreement with other in vitro studies $(2,5)$.

SSc fibroblasts at the $4^{\text {th }}$ passage were conditioned with or without pre-treatment for $1 \mathrm{~h}$ with $\mathrm{ET}_{\mathrm{A}} \mathrm{RA}(2 \mu \mathrm{M})$ or $\mathrm{ET}_{\mathrm{A} / \mathrm{B}} \mathrm{RA}(10$ $\mu \mathrm{M})$ and then treated with ET-1 $(100 \mathrm{nM})$ for 24 and $48 \mathrm{hrs}$ in order to test the effects of the ET receptor antagonists. SSc fibroblasts were also treated with $\mathrm{ET}_{\mathrm{A}} \mathrm{RA}$ $(2 \mu \mathrm{M})$ and $\mathrm{ET}_{\mathrm{A} / \mathrm{B}} \mathrm{RA}(10 \mu \mathrm{M})$ alone for 24 and 48 hrs. Primary cultures of human SSc skin fibroblasts not treated with ET-1 or ET receptor antagonists $\left(\mathrm{ET}_{\mathrm{A}} \mathrm{RA}\right.$ and $\left.\mathrm{ET}_{\mathrm{A} / \mathrm{B}} \mathrm{RA}\right)$ were used as controls. Normal fibroblast cultures have been previously tested in our laboratory and were found to be responsive to ET-1 treatment in the same way as SSc fibroblasts (6). For ethical reasons, in this in vitro study, new biopsies from healthy subjects were not performed.

\section{Immunocytochemistry}

SSc fibroblasts at the $4^{\text {th }}$ passage were cultured in Flexi PERM chamber slides $\left(1 \times 10^{4}\right.$ cells/spot) and treated according to the experimental design. At the end of treatment, the cells were incubated with primary antibodies to human FN (dilution 1:100, Sigma-Aldrich), COL-1 (dilution 1:100, Abcam, Cambridge, UK) and FBL1 (dilution 1:100, Millipore, Billerica, MA, USA). Linked antibodies were detected by biotinylated universal secondary antibody and subsequently with horseradishperoxydase-streptavidine complex (Vector Laboratories, Burlingame, CA, USA). The slide evaluation was performed on 30 light power fields for each condition by light microscopy (magnification 40X) and computerized image analysis with Leica Q500MC Image Analysis System (Leica, Cambridge, UK).

\section{Western blot analysis}

SSc fibroblasts at the $4^{\text {th }}$ passage, cultured up 
to $80 \%$ of confluence, were treated according to the experimental design. At the end of treatment, the cells were lysed with $\mathrm{Nu}-$ cleoSpin RNA/protein (Macherey-Nagel, Duren, Germany) and protein quantification was performed by the Bradford method.

For every condition, $15 \mu \mathrm{g}$ of protein were separated by electrophoresis on a $10 \%$ sodium dodecyl sulfate polyacrylamide electrophoresis (SDS-PAGE) gel and transferred into Hybond-C-nitrocellulose membrane (GeHealthcare, Milan, Italy). Membranes were incubated in a blocking solution (PB$\mathrm{S} 1 \mathrm{x}, 0.1 \%$ triton-X and $5 \%$ non-fat powdered milk) and subsequently with primary antibodies to human FN (dilution 1:1000, Sigma-Aldrich), COL-1 (dilution 1:4000, Abcam), FBL-1 (dilution 1:500, Millipore) and actin (dilution 1:2000, DB Biotech, Kosice, Slovakia) at $4^{\circ} \mathrm{C}$ overnight.

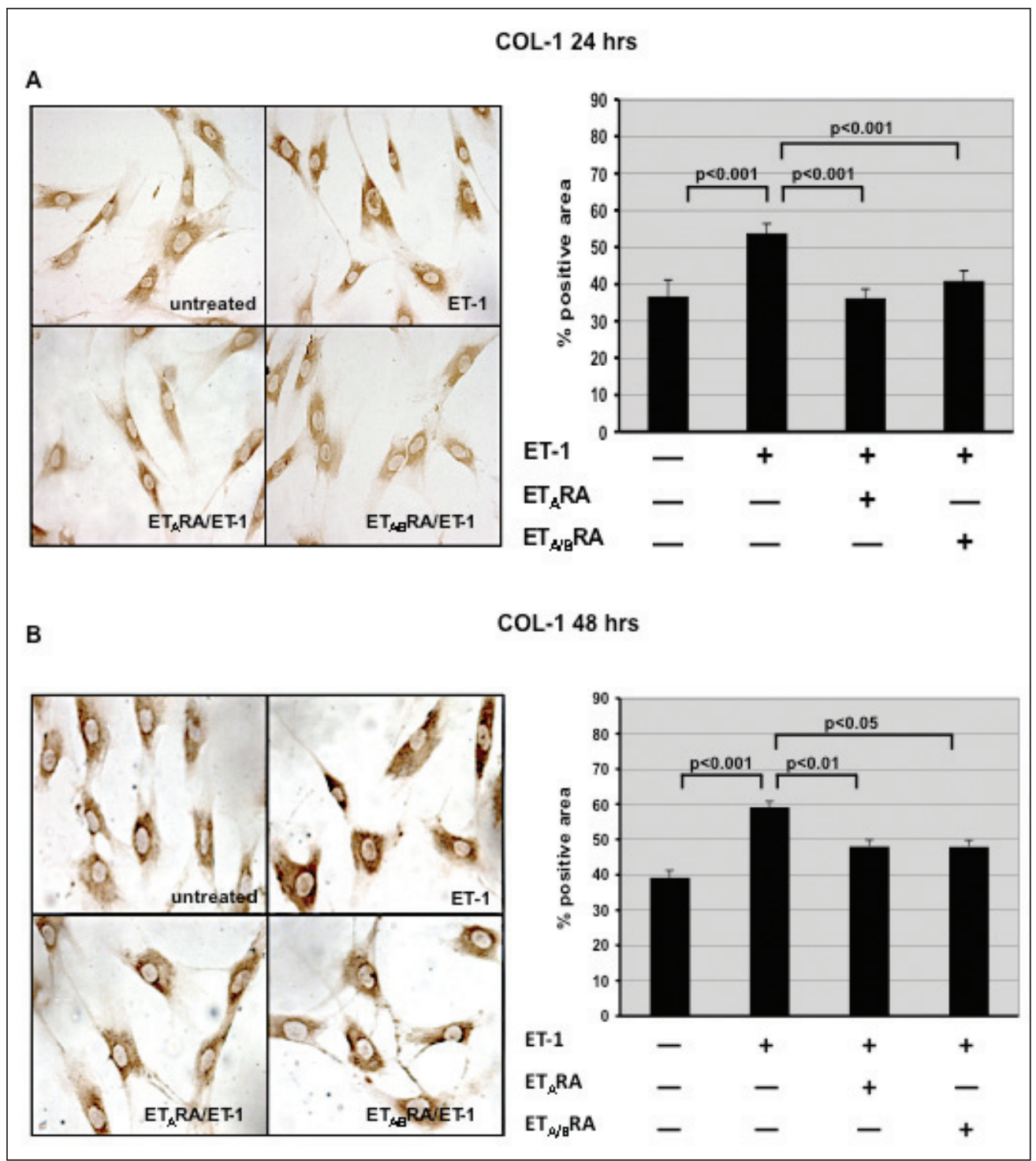

Figure 1 - Immunocytochemistry of type I collagen (COL-1) synthesis at 24 and 48 hours. (A) In vitro evaluation by immunocytochemistry and relative image analysis of COL-1 synthesis in primary cultures of SSc skin fibroblasts at $24 \mathrm{hrs}$ and (B) $48 \mathrm{hrs}$. ET-1, endothelin-1 [100 nM]; $E_{A} R A$, endothelin-A receptor antagonist $[2 \mu \mathrm{M}] ; \mathrm{ET}_{A B} R A$, endothelin-A/B receptor antagonist $[10 \mu \mathrm{M}]$. 
Membranes were subsequently incubated with secondary antibodies: anti-mouse Ig for FN and FBL-1 (dilution 1:10000, GeHealthcare), and anti-rabbit Ig for COL-1 and actin (dilution 1:10000, Santa Cruz Biotechnology, California, USA). Protein synthesis was detected using the enhanced chemiluminescence system (Immobilon-P, Millipore, USA).

Densitometric analysis of Western blotting was performed by computerized im- age analysis with Leica Q500MC Image Analysis System (Leica). Protein synthesis was evaluated by the quantification of pixel intensity and indicated as positive area.

\section{Statistical analysis}

Statistical analysis was carried out by nonparametric test. Friedman's test was performed to compare the paired treatments. A $\mathrm{P}$ value $<0.05$ was considered statistically significant.

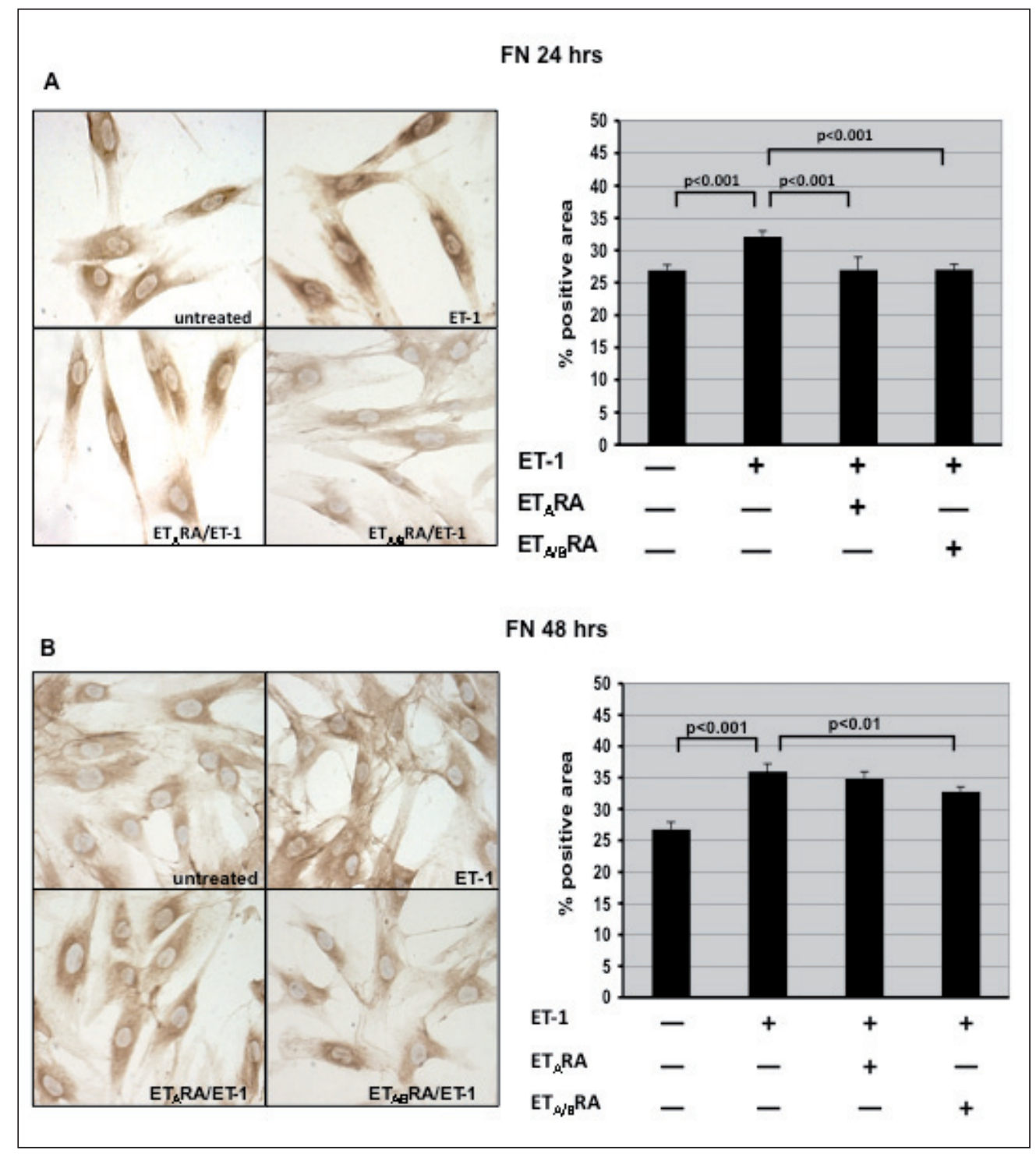

Figure 2 - Immunocytochemistry of fibronectin (FN) synthesis at 24 and 48 hours. (A) In vitro evaluation by immunocytochemistry and relative image analysis of FN synthesis in primary cultures of SSc skin fibroblasts at 24 hrs and (B) 48 hrs. ET-1, endothelin-1 [100 nM]; ET RA, endothelin-A receptor antagonist $[2 \mu \mathrm{M}] ; \mathrm{ET}_{\mathrm{A} / \mathrm{B}} \mathrm{RA}$, endothelin-A/B receptor antagonist [10 $\left.\mu \mathrm{M}\right]$. 


\section{RESULTS}

Effects of ET-1 on ECM protein synthesis Results showed that ET-1 significantly increased COL-1 and FN synthesis both at 24 and $48 \mathrm{hrs}(\mathrm{P}<0.001$ for every protein $)$ vs untreated fibroblasts (Fig. 1 and 2). ET-1 was able to increase the FBL-1 synthesis after 48 hrs of treatment $(\mathrm{P}<0.001)$, whereas no difference was observed at $24 \mathrm{hrs} v \mathrm{~s}$ untreated fibroblasts (Fig. 3). These data were obtained by immunocytochemistry and relative image analysis. COL-1, FN and FBL-1 synthesis was also investigated by Western blotting and relative densitometric analysis. Results showed that ET-1 was able to induce a statistically significant increase in COL-1 and FN synthesis both at 24 hrs $(\mathrm{P}<0.01$ for both $)$ and $48 \mathrm{hrs}$ $(\mathrm{P}<0.05$ for both) vs untreated fibroblasts (Fig. 4). Finally, FBL-1 production was found significantly increased only at $48 \mathrm{hrs}$

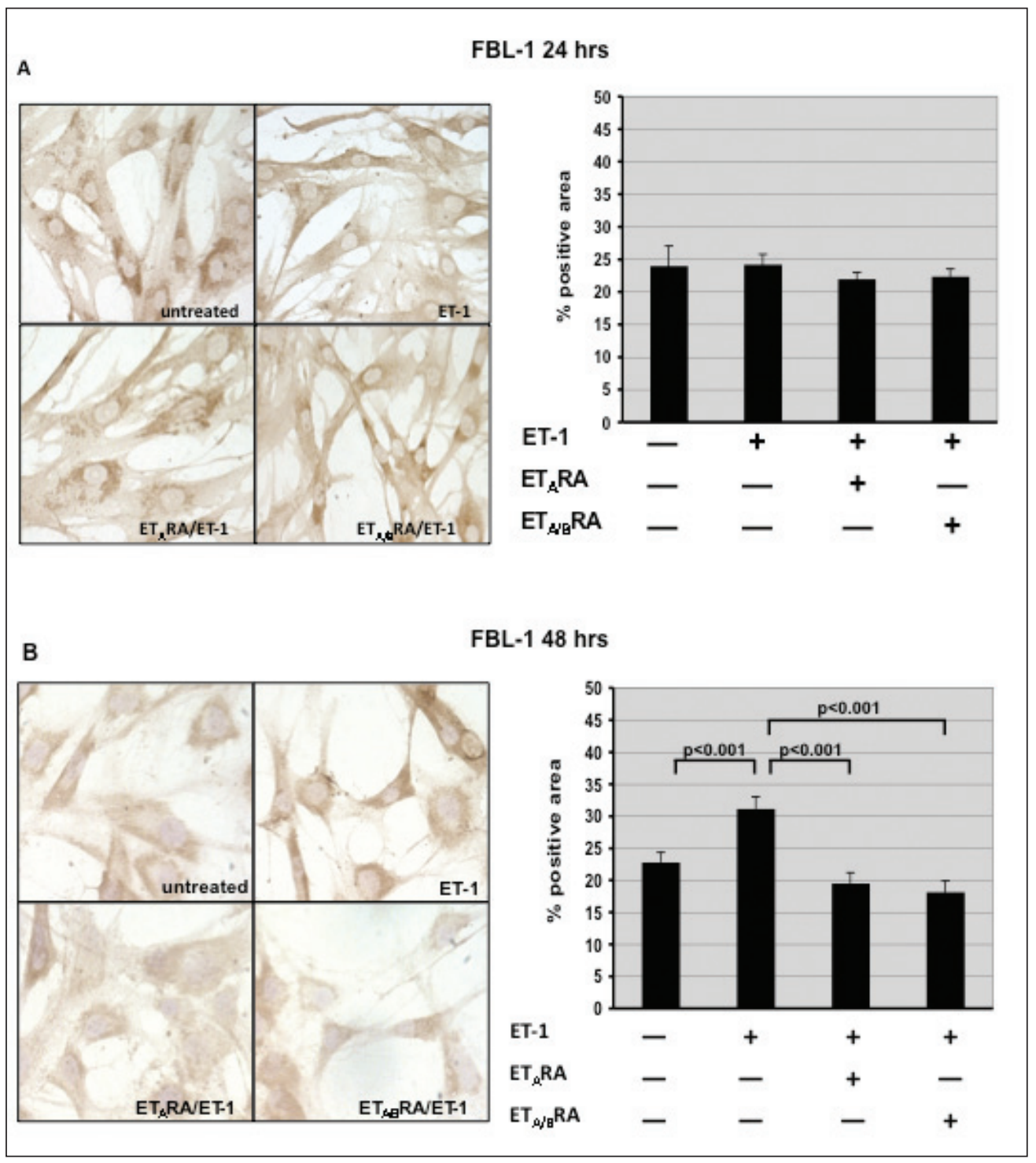

Figure 3 - Immunocytochemistry of fibrillin-1 (FBL-1) synthesis at 24 and 48 hours. (A) In vitro evaluation by immunocytochemistry and relative image analysis of FBL-1 synthesis in primary cultures of SSc skin fibroblasts at $24 \mathrm{hrs}$ and (B) $48 \mathrm{hrs}$. ET-1, endothelin-1 [100 nM]; ET RA, endothelin-A receptor antagonist $[2 \mu \mathrm{M}] ; \mathrm{ET}_{\mathrm{A} / \mathrm{B}} \mathrm{RA}$, endothelin-A/B receptor antagonist [10 $\left.\mu \mathrm{M}\right]$. 
by ET- 1 treatment $v s$ untreated fibroblasts $(\mathrm{P}<0.05)$ (Fig. 4B).

\section{Effects of ET receptor antagonists on} ECM protein synthesis

Immunocytochemistry and Western blot- ting analysis were performed to detect the in vitro effects of ET receptor antagonists on ECM protein synthesis. At $24 \mathrm{hrs}$, both $\mathrm{ET}_{\mathrm{A}} \mathrm{RA}$ and $\mathrm{ET}_{\mathrm{A} / \mathrm{B}} \mathrm{RA}$ significantly antagonized the ET-1-mediated increase in COL$1(\mathrm{P}<0.001$ for both) and $\mathrm{FN}(\mathrm{P}<0.001$ for

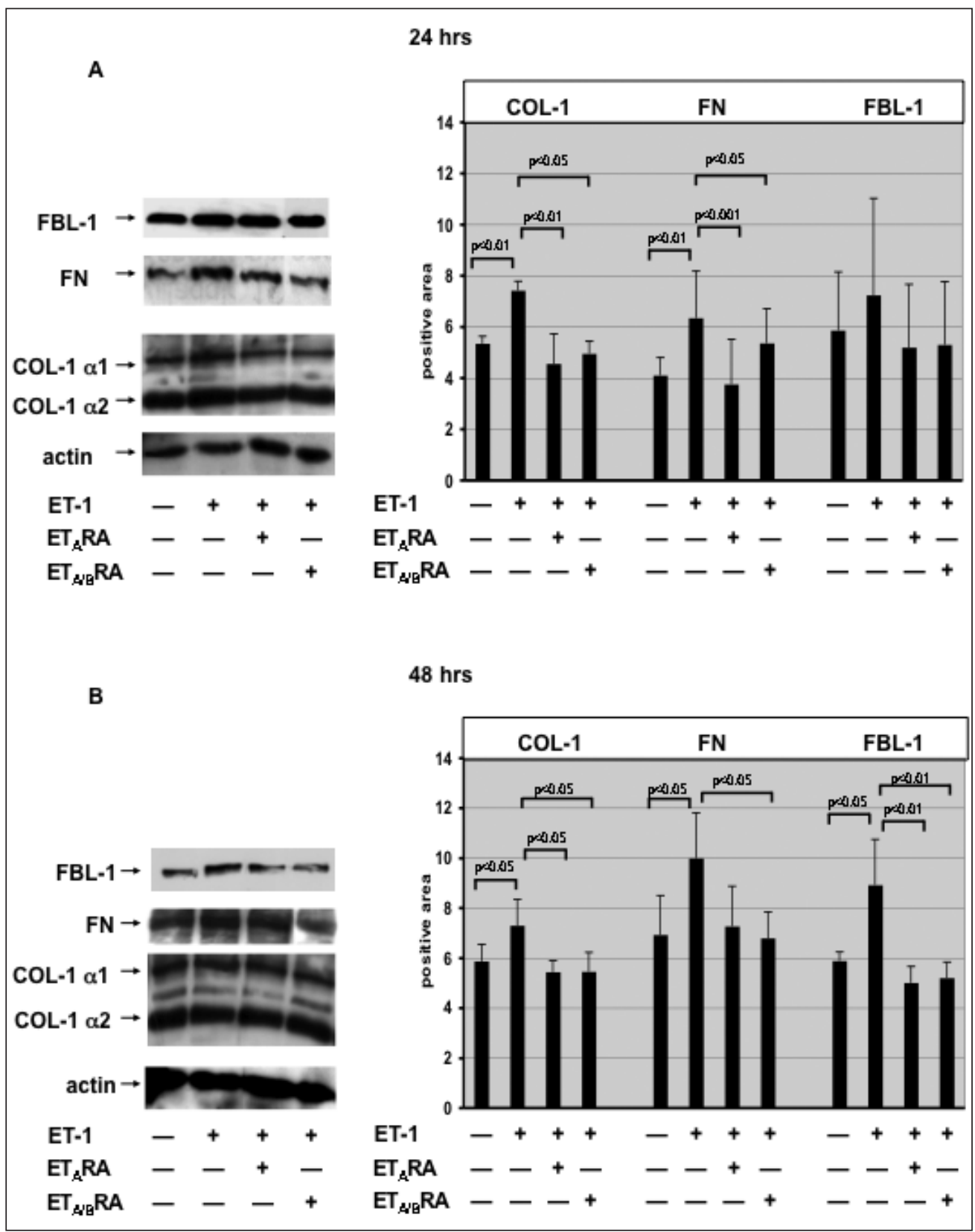

Figure 4 - Western blotting analysis of ECM protein synthesis at 24 and 48 hours. (A) In vitro evaluation by Western blotting and relative densitometric analysis of type I collagen (COL-1), fibronectin (FN), fibrillin-1 (FBL-1) and actin synthesis in primary cultures of SSc skin fibroblasts at $24 \mathrm{hrs}$ and (B) $48 \mathrm{hrs}$. ET-1, endothelin-1 [100 nM]; ET RA, endothelin-A receptor antagonist $[2 \mu \mathrm{M}] ; \mathrm{ET}_{\mathrm{A} / \mathrm{B}} \mathrm{RA}$, endothelin-A/B receptor antagonist [10 $\left.\mu \mathrm{M}\right]$. 
both) synthesis, whereas no significant difference was observed in FBL-1 synthesis vs ET-1-treated fibroblasts (Fig. 1A, 2A and $3 \mathrm{~A})$. At $48 \mathrm{hrs}, \mathrm{ET}_{\mathrm{A}} \mathrm{RA}$ still significantly contrasted the increase in COL- 1 and FBL1 synthesis induced by ET- $1(\mathrm{P}<0.01$ and $\mathrm{P}<0.001$, respectively), but it lost any effect on FN synthesis vs ET-1-treated cells (Fig. 1B, 2B and 3B). On the contrary, at 48 hrs $\mathrm{ET}_{\mathrm{A} / \mathrm{B}} \mathrm{RA}$ still significantly antagonized the ET-1-mediated increase in all the investigated ECM protein synthesis $(\mathrm{P}<0.05$ for COL-1; $\mathrm{P}<0.01$ for $\mathrm{FN} ; \mathrm{P}<0.001$ for FBL1 vs ET-1-treated fibroblasts) (Fig. 1B, 2B and $3 \mathrm{~B})$. The effect of $\mathrm{ET}_{\mathrm{A} / \mathrm{B}} \mathrm{RA}$ treatment on FN was found sustained also at $72 \mathrm{hrs}$ (data not shown). These data were obtained by immunocytochemistry and relative image analysis.

Western blotting analysis confirmed the results observed by immunocytochemistry showing that both $\mathrm{ET}_{\mathrm{A}} \mathrm{RA}$ and $\mathrm{ET}_{\mathrm{A} / \mathrm{B}} \mathrm{RA}$ significantly antagonized COL-1 $(\mathrm{P}<0.01$ and $\mathrm{P}<0.05$, respectively) and FN synthesis induced by ET-1 $(\mathrm{P}<0.001$ and $\mathrm{P}<0.05$, respectively) at 24 hrs vs ET-1-treated fibroblasts (Figure 4A). At 48 hrs, ET RA contrasted the ET-1-mediated increase in both COL-1 and FBL-1 synthesis $(\mathrm{P}<0.05$ and $\mathrm{P}<0.01$, respectively) whereas no difference was observed for FN vs ET-1-treated fibroblasts (Figure 4B). Conversely, $\mathrm{ET}_{\mathrm{A} / \mathrm{B}} \mathrm{RA}$ maintained the ability to antagonize the increase in synthesis of all the investigated ECM proteins induced by ET- 1 also at $48 \mathrm{hrs}$ of treatment vs ET-1-treated cells $(\mathrm{P}<0.05$ for COL-1 and FN; $\mathrm{P}<0.01$ for FBL-1) (Figure $4 \mathrm{~B})$. The effect of $\mathrm{ET}_{\mathrm{A} / \mathrm{B}} \mathrm{RA}$ treatment on $\mathrm{FN}$ was found sustained also at $72 \mathrm{hrs}$ (data not shown). The SSc skin fibroblasts were also treated with $\mathrm{ET}_{\mathrm{A}} \mathrm{RA}$ or $\mathrm{ET}_{\mathrm{A} / \mathrm{B}} \mathrm{RA}$ alone and it was shown that both ET receptor antagonists reduced COL-1 and FN synthesis, especially after $24 \mathrm{hrs}$, and FBL-1 synthesis at $48 \mathrm{hrs}$, but this was not statistically significant (data not shown).

\section{DISCUSSION}

The present in vitro study investigated the effects of the single and dual ET-1 receptor antagonists $\left(\mathrm{ET}_{\mathrm{A}} \mathrm{RA}\right.$ and $\mathrm{ET}_{\mathrm{A} / \mathrm{B}} \mathrm{RA}$ ) on the ET-1-induced increase in ECM protein synthesis (COL-1, FN and FBL-1) in primary cultures of SSc skin fibroblasts. Firstly, results confirm that ET-1 is able to induce a significant increase in the synthesis of all the evaluated ECM proteins, supporting a possible involvement of this potent soluble vasoconstrictor also in the development of SSc skin fibrosis, as proposed in other conditions (10).

In particular, endogenous ET-1 signalling was previously found to contribute to COL-1 and connective tissue growth factor (CTGF) overexpression in fibrotic fibroblasts (11).

However, recent reports support the pro-fibrotic role of ET-1 in vitro by showing that TGF- $\beta 1$ and ET- 1 may act in cooperation to induce the acquisition of pro-fibrotic phenotype in human normal skin fibroblasts and suggesting a possible synergistic role of the TGF- $\beta 1 / E T-1$ axis in the development of fibrosis $(2,5)$.

Therefore, since ET-1 via $\mathrm{ET}_{\mathrm{A}}$ and $\mathrm{ET}_{\mathrm{B}}$ receptors contributes to the ability of TGF- $\beta$ to promote a pro-fibrotic phenotype, this effect is consistent with the notion that ET-1 receptor antagonism may be beneficial in potentially controlling the fibrogenic responses in lung fibroblasts and might represent an important strategy to contrast the profibrotic effects of ET-1 on SSc progression $(2,5,10,12,13)$.

The results showed that the single $\mathrm{ET}_{\mathrm{A}} \mathrm{RA}$ was able to down-regulate the ET-1-mediated increase in COL-1 and FN synthesis in the short term, whereas the dual $\mathrm{ET}_{\mathrm{A} / \mathrm{B}} \mathrm{RA}$ induced a more prolonged and significant effect in reducing especially the ET-1-mediated increase of FN synthesis, together with COL-1.

Interestingly, since COL-1-containing fibrils do not form in the absence of increased FN and FN-binding and collagenbinding integrins, the best target to control the progression of the fibrotic process seems to be the increased FN (and integrins as organizers) (14). The capability of $\mathrm{ET}_{\mathrm{A}} \mathrm{RA}$ and $\mathrm{ET}_{\mathrm{A} / \mathrm{B}} \mathrm{RA}$ to antagonize the ET-1-induced ECM increase in cultured SSc fibroblasts and, in particular, the more 
sustained inhibitory effects exerted by the $\mathrm{ET}_{\mathrm{A} / \mathrm{B}} \mathrm{RA}$ on FN synthesis, seems to support some of the clinical aspects. For example, recent clinical studies showed that the recognized effect of $\mathrm{ET}_{\mathrm{A} / \mathrm{B}} \mathrm{RA}$ antagonist in preventing digital ulcers may also be effective in reducing skin fibrosis in patients with $\operatorname{SSc}(4,15,16)$.

Finally, the analysis of FBL-1 showed that ET-1 increased the synthesis of this protein and this increase was temporarily secondary to the COL-1 and FN. As we know, FBL-1 is the main component of ECM microfibrils and plays an important role on the profibrotic phenotype of SSc fibroblasts (17). As observed for COL-1 and FN, the $\mathrm{ET}_{\mathrm{A}} \mathrm{RA}$ and $\mathrm{ET}_{\mathrm{A} / \mathrm{B}} \mathrm{RA}$ contrasted significantly with the increase in FBL-1 synthesis induced by ET-1, an effect that might be the consequence of a general downregulation of the ECM synthesis exerted by these antagonists.

In agreement with these results, a recent study showed that in SSc, dermal fibroblasts the microfibril abnormalities might be a secondary event of matrix deregulation and in ECM remodeling, probably due to the alteration of proteolitic process induced by growth factors (i.e., TGF- $\beta$ ) that characterize the SSc fibrotic process (18).

\section{CONCLUSIONS}

In conclusion, in vitro interference of the ET receptor antagonism with the ECM protein synthesis and the resultant possible therapeutic effect on progressive fibrosis, suggest that ET antagonism agents could act as potential disease modifying molecules in combination therapies for $\mathrm{SSc}$ (18).

\section{FUNDINGS}

The research was supported by official research grants to the University of Genova from Actelion Pharmaceuticals and Pfizer.

\section{ACKNOWLEDGMENTS}

This in vitro study was supported by a research grant from Actelion Pharmaceu- ticals that provided the endothelin- $A / B$ receptor antagonist (bosentan) and by $a$ research grant from Pfizer that provided the endothelin-A receptor antagonist (sitaxentan).

\section{REFERENCES}

1. Wei J, Bhattacharyya S, Tourtellotte W, Varga J. Fibrosis in sistemic sclerosis: emerging concepts and implications for targeted therapy. Autoimmun Rev. 2011; 10: 267-75.

2. Asano Y. Future treatments in systemic sclerosis. J Dermatol. 2010; 37: 54-70.

3. Wynn TA. Cellular and molecular mechanisms of fibrosis. J Pathol. 2008; 214: 199-210.

4. Leask A. The role of endothelin-1 signaling in the fibrosis observed in systemic sclerosis. Pharmacol Res. 2011; 63: 502-3.

5. Lagares D, Garcia-Fernandez R, Jimenez CL, et al. Endothelin 1 contributes to the effect of transforming growth factor 1 on wound repair and skin fibrosis. Arthritis Rheum. 2010; 62: 878-89.

6. Laesk A. Targeting the TGFbeta, endotheli-1 and CCN2 axis to combact fibrosis in scelroderma. Cell Signal. 2008; 20: 1409-14.

7. Soldano S, Montagna P, Villaggio B, et al. Endothelin and sex hormones modulate the fibronectin synthesis by cultured human skin scleroderma fibroblasts. Ann Rheum Dis. 2009; 68: 599-602.

8. Shi-wen X, Kennady L, Renzoni A, et al. Endothelin is a downstream mediator of profibrotic responces to transforming growth factor in human lung fibroblasts. Arthrit Rheum. 2007; 56: 4189-94.

9. Sticherling M. The role of endothelin in connective tissue diseases. Rheumatology (Oxford). 2006; 45 (Suppl. 3): iii8-10.

10. Abraham DJ, Krieg T, Distler J, et al. Overview of pathogenesis of systemic sclerosis. Rheumatology (Oxford). 2009; 48 (Suppl. 3): iii3-7.

11. Shi-Wen X, Renzoni EA, Kennedy L, et al. Endogenous endothelin-1 signaling contributes to type I collagen and CCN2 overexpression in fibrotic fibroblasts. Matrix Biol. 2007; 26: 625-32.

12. Schneider MP, Boesen EI, Pollock DM. Contrasting action of ETA and ETB receptors in vascular disease. Ann Rev Pharmacol Toxicol. 2007; 47: 731-59.

13. Cardillo C, Schinzari F, Melina D, et al. Improved endothelial function after endothelin receptor blockage in patients with systemic sclerosis. Arthritis Rheum. 2009; 60: 1840-4.

14. Kadler KE, Hill A, Canty-Laird EG. Collagen fibrillogenesis: fibronectin, integrins, and 
minor collagens as organizers and nucleators. Curr Opin Cell Biol. 2008; 20: 495-501.

15. Kuhn A, Haust M, Ruland V, et al. Effect of bosentan on skin fibrosis in patients with systemic sclerosis: a prospective, open-label, non-comparative trial. Rheumatology (Oxford). 2010; 49: 1336-45.

16. Lambova S, Muller-Ladner U. Connective tissue diseases: treatment of digital ulcers in systemic sclerosis. Nat Rev Rheumatol. 2011; 7: 5-6.
17. Tan FK, Arnett FC, Antohi S, et al. Autoantibodies to the extracellular matrix microfibrillar protein, fibrillin-1, in patients with systemic scleroderma and other connective tissue diseases. J Immunol. 1999; 163: 1066-72.

18. Wipff J, Avouac J, Le Charpentier M, et al. Dermal tissue and cellular expression of fibrillin-1 in diffuse cutaneous systemic sclerosis. Rheumatology (Oxford). 2010; 49: 657-61. 